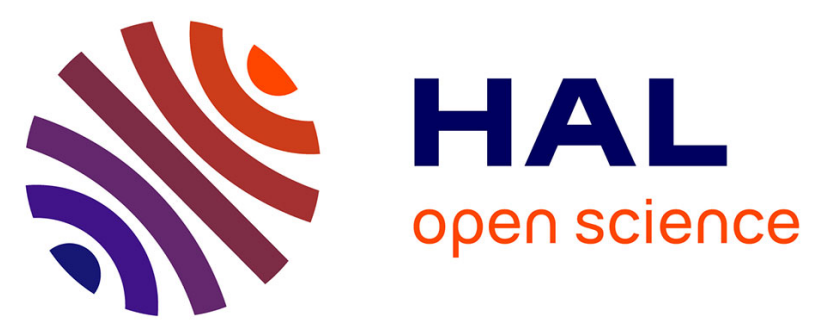

\title{
Association between excreta management and incidence of extended-spectrum $\beta$-lactamase-producing Enterobacteriaceae: role of healthcare workers' knowledge and practices
}

\author{
T.T.H. N'Guyen, C. Bourigault, V. Guillet, A-C. Guille Des Buttes, E. \\ Montassier, E. Batard, G. Birgand, D. Lepelletier
}

\section{To cite this version:}

T.T.H. N'Guyen, C. Bourigault, V. Guillet, A-C. Guille Des Buttes, E. Montassier, et al.. Association between excreta management and incidence of extended-spectrum $\beta$-lactamase-producing Enterobacteriaceae: role of healthcare workers' knowledge and practices. Journal of Hospital Infection, 2019, 102, pp.31 - 36. 10.1016/j.jhin.2018.12.006 . hal-03486717

\section{HAL Id: hal-03486717 https://hal.science/hal-03486717}

Submitted on 20 Dec 2021

HAL is a multi-disciplinary open access archive for the deposit and dissemination of scientific research documents, whether they are published or not. The documents may come from teaching and research institutions in France or abroad, or from public or private research centers.
L'archive ouverte pluridisciplinaire HAL, est destinée au dépôt et à la diffusion de documents scientifiques de niveau recherche, publiés ou non, émanant des établissements d'enseignement et de recherche français ou étrangers, des laboratoires publics ou privés.

\section{(ㅇ)(1) $\$$}

Distributed under a Creative Commons Attribution - NonCommerciall 4.0 International 
Version of Record: https://www.sciencedirect.com/science/article/pii/S0195670118307102

Manuscript_fd13e63132edbc5ea971a1e7b2c45161

Title

Association between excreta management and extended-spectrum $\beta$-lactamase producing

Enterobacteriaceae incidence rate: Role of health-care worker's knowledge and practices

\section{Authors}

N'Guyen Thi Thanh Ha ${ }^{a}$, Bourigault Céline ${ }^{a, b}$, Guillet Vanessa ${ }^{b}$, Guille des Buttes Anne-Claire ${ }^{b}$, Montassier Emmanuel ${ }^{a, c}$, Batard Eric $^{a, c}$, Birgand Gabriel ${ }^{a, d}$, Lepelletier Didier ${ }^{a, b *}$

\section{Affiliation}

${ }^{a}$ MiHAR Lab (www.mihar.univ-nantes.fr), University of Nantes, Nantes, FR-44000

${ }^{\mathrm{b}}$ Bacteriology and Infection Control Department, Nantes University Hospital, Nantes, FR-44000

${ }^{\mathrm{C} E m e r g e n c y ~ D e p a r t m e n t, ~ N a n t e s ~ U n i v e r s i t y ~ H o s p i t a l, ~ N a n t e s, ~ F R-44000 ~}$

${ }^{\mathrm{d}}$ Regional Infection Control Center, Pays de la Loire, Nantes, FR-44000

\section{Corresponding author}

*Prof. Didier Lepelletier (mail: didier.lepelletier@chu-nantes.fr), MiHAR Lab (www.mihar.univnantes.fr), University of Nantes, Nantes, FR-44000

Previous presentation: Results of this study were presented in part at the 25th European Congress of Clinical Microbiology and Infectious Diseases in Amsterdam, Netherlands, 09 - 12 April 2016. 


\section{SUMMARY}

Background: The spread of extended-spectrum $\beta$-lactamase producing Enterobacteriaceae (ESBL$\mathrm{PE}$ ) in healthcare environments has become a major public health threat in recent years.

Aim: To assess how healthcare workers (HCWs) manage excreta and the possible association with ESBL-PE incidence.

Methods: $800 \mathrm{HCWs}$ and 74 nurse-supervisors were questioned through 2 self-report questionnaires in order to assess their knowledge and practices, and to determine the equipment utilized for excreta management in 74 healthcare departments. The performance on equipment utilized, knowledge and practices were scored as good (score 1), intermediate (score 2) or bad (score 3) on the basis of pre-established thresholds. Linear regression was performed for evaluating the association between HCWs knowledge/practices and ESBL-PE incidence.

Findings: $688 \mathrm{HCWs}(86 \%)$ and all nurse-supervisors participated to the survey. Proportions of scores 1, 2 and 3 were: 14.8\%, 71.6\% and 17.6\% for equipment; $30.1 \%, 40.6 \%$ and $29.3 \%$ for knowledge; and $2.0 \%, 71.9 \%$ and $26.1 \%$ for practices. The single regression mathematic model highlighted that bad practices (score 3) from HCWs were significantly associated with increased ESBL-PE incidence $(p=0.002)$.

Conclusions: HCWs' practices for managing excreta positively correlated with ESBL-PE incidence, especially in surgical units. Public health efforts to enhance knowledge and practices of HCWs urgently need to be developed and integrated, within infection control programs, to better control the spread of multidrug-resistant bacteria.

Key-words: ESBL-PE; excreta; hospital practices; infection control. 


\section{INTRODUCTION}

Controlling the spread of extended-spectrum $\beta$-lactamase producing Enterobacteriaceae (ESBL-PE) is challenging because of their pathogenicity, and their dissemination within both hospital and community settings [1-2]. Patients' colonization by Escherichia coli or Klebsiella pneumoniae within their digestive tract [3] can be sustainable over several months after hospital discharge, which may facilitate spread in the general population [4]. The ESBL-PE prevalence varies worldwide but their presence is now relatively common in healthcare settings [5] and in animals [6]. In France, since 2006, multidrug-resistant organisms surveillance programs have been focused on ESBL-PE, highlighting an increase in ESBL-PE incidence rate in French healthcare settings despite the implementation of infection control (IC) strategies [7].

This concerning endemic situation must be controlled in order to limit the emergence of carbapenemase-producing Enterobacteriaceae, through importation from patients hospitalized abroad and due to cross-transmission in French hospitals and worldwide [8-11]. High concentrations of ESBL-PE are found in human feces (around $10^{8}$ ESBL per gram wet weight), particularly in patients exposed to antibiotics [12]. These multidrug-resistant organisms can spread in hospital from the gut through different ways: from patient to patient, by hands of healthcare workers (HCWs) or patient room contamination $[13,14]$. This risk may be related to the quality of the equipment and materials in the hospital settings and to the level of knowledge and practices of HCWs regarding excreta management. Lepainteur et al. showed that only $19 \%$ of HCWs directly disinfected bedpans in bedpan washer-disinfectors, and the majority (71\%) rinsed bedpans, often in patient restrooms (62\%) before disinfection in washer-disinfector [15]. In the context of a local endemic ESBL-PE situation, we performed a quantitative study to assess hospital equipment, and 
HCWs knowledge and practices related to excreta management; and its possible association with ESBL-PE incidence rate in a large university hospital. 


\section{MATERIAL AND METHODS}

\section{Study design, inclusion of healthcare Departments and HCWs}

The survey was conducted at Nantes University Hospital during a 3-month period from January to March, 2014. We used the institutional infection control referent network to include HCWs. This network includes about 280 nurses and assistant-nurses working through 74 healthcare units ( Medicine = 33; Surgical = 31; Physical medicine and rehabilitation = 5; Long term care facilities = 5) . All referents received a letter asking them to participate in the survey and to complete one questionnaire related to their knowledge and practices about excreta collection and elimination. Several questionnaires were also available in each unit and could be answered by other HCWs. At the same time, the nurse-supervisor of each healthcare units had to complete a single questionnaire related to the excreta equipment.

\section{Data collection}

Questions related to healthcare units' equipment, knowledge, and practices of HCWs included 13, 7 and 13 items, respectively. Three scores were calculated by summarizing all the item responses and one point was given for each positive answer (yes=1 point; no=0 point) as follows:

- Healthcare units' equipment: Score 1 (Well-equipped units: 11 to 13 points), score 2 (Intermediate: 7 to 10 points) and score 3 (Bad-equipped units: 0 to 6 points),

- HCWs' knowledge: Score 1 (HCW with high level of knowledge: 7 points), score 2 (HCW with intermediate level of knowledge: 5 to 6 points), score 3 (HCW with low level of knowledge: 0 to 4 points),

- HCWs' practices: Score 1 (HCWs with high level of practice: 10 to 13 points), score 2 (HCWs with intermediate level of practice: 6 to 9 points), score 3 (HCWs with low level of practice: 0 
to 5 points). One point was scored when the answer was "always" or "never" according to the question.

Data related to ESBL-PE incidence were collected from the laboratory database with an automatic daily alert. Incidence rate was stratified by type of healthcare units included in the study. Incidence rate was the ratio between the number of patients with ESBL-PE hospitalized in 2015 (numerator) and the cumulated number of patient-days (denominator) $\times 1,000$. ESBL-PE incidence rate was coded 1 if it was higher than or equal to the global hospital median ESBL-PE incidence rate (0.47/ 1,000 patient-days [0.03-0.97]) and coded 0 if it was lower. The alcohol hand rub variable was coded as 1 if it was higher than or equal to the global hospital median consumption $(36.67 / 1,000$ patient-days [7.37-41.39]) and coded 0 if it was lower.

\section{Data management and analysis}

Data were collected using Sphinx Plus-V5 ${ }^{\circledR}$ software (Chavanod, France). Data were described using the median and interquartile ranges for continuous variables and proportions (\%) for categorical variables. A simple linear regression was performed using STATA V15 ${ }^{\circledR}$ software (StataCorp LP, Texas, USA) to examine the relation between scores of performance (predictor continuous variable) and the ESBL-PE incidence rate or alcohol hand rub consumption. Correlation coefficients $\mathrm{R}$ were tested and all $P$ values were two sided. $P$ values $<0.05$ were considered significant. 


\section{RESULTS}

\section{Equipment of healthcare units}

All nurse supervisors participated in the study. Sixty-six of them (93\%) reported that each healthcare unit was equipped with at least one washer disinfector for every 21 beds. The washer disinfector room was shared between disinfection of bedpans or urine bottles and other medical devices, in half of the cases (37/74). Approximately $32 \%$ of patient rooms in healthcare units (24/74) were equipped with a hand shower for cleaning bedpans and urine bottles. The number of available bedpans and urine bottles were reported to be sufficient by $80 \%$ of nurse supervisors.

Only $13 \%$ and $25 \%$ of HCWs used covers to transport bedpans and urine bottles from the patient room to the washer disinfector room, respectively. Alcohol hand rub was not available in the washer disinfector room in $24 \%$ of healthcare units. Individual protection for collecting excreta was used by assistant nurses in 93\% of healthcare units. According to the 13 evaluation items (Table 1), 8/74 healthcare units (10.8\%) had a performance score of 1 (Good equipment), 53 (71.6 \%) had a score 2 (Intermediate) and 13 (17.6\%) had a score 3 (bad equipment).

\section{Participants (HCWs)}

Eight hundred questionnaires were distributed through the 74 healthcare units. Six hundred and eighty-eight HCWs completed the questionnaire with a participation rate of $86 \%(688 / 800)$. Participants were assistant-nurses $(332 / 688,48 \%)$, nurses $(311 / 688,45 \%)$ or other staff members (46/688, 7\%). HCWs were working in medical units $(41 \%)$, in surgical units $(39 \%)$, in physical medicine and rehabilitation units (15\%) and in long term care facilities (5\%). 


\section{HCWs knowledge evaluation}

595 HCWs (86.4\%) reported to know that excreta disposal in patients' rooms was forbidden and environment contamination from gut flora and may contribute to the spread of multidrug-resistant microorganisms. Most of HCWs (80.9\%) reported to understand that using the hand shower available in patients' rooms to clean urine bottles and bedpans was a major risk factor associated with environment contamination particularly in patient colonized with multidrug-resistant microorganisms. Only $12 \%$ of HCWs reported to have been trained on the topic within the last 10 years; $63 \%$ of $\mathrm{HCW}$ reported the need to be better trained, to understand excreta management and environmental contamination. All the other reporting related to $\mathrm{HCWs}^{\prime}$ knowledge are summarized in table 2. According to the 7 evaluation items, $207 \mathrm{HCWs}$ (30.1\%) had a score 1 (good knowledge), 279 HCWs (40.6 \%) had a score 2 (intermediate knowledge) and 202 HCWs (29.3\%) had a score 3 (bad knowledge). Bad knowledge level (score 3) distribution increased from long term care facilities $(0 \%)$, to physical medicine and rehabilitation department (30.0\%), medical units (27.9\%) and surgical units (41.3\%).

\section{HCWs practice evaluation}

357 HCWs (51.9\%) reported to always or often empty excreta (urine and feces) in patients' bathrooms; 35\% (240/688) HCWs reported to the hand shower for equipment rinsing (urine bottle and bedpans) in the patient's bathroom. The evaluation of the main practices related to excreta collection and elimination are summarized in Table 3. According to the 13 evaluation items, 14 HCWs (2.0\%) had a score 1 (good practices), 495 HCWs (71.9 \%) had a score 2 (intermediate level) and 179 HCWs (26.1\%) had a score 3 (bad practices). Bad practice level (score 3) distribution increased from long term care facilities (0\%), to physical medicine and rehabilitation units (18.5\%), medical units (21.2\%) and surgical units (41.8\%) (Table 4). 


\section{ESBL-PE incidence rates and alcohol hand rub consumption}

ESBL-PE incidence rates per 1000 patient-days were $0.97(0.45-1.12)$ in surgical units, 0.54 (0.41$0.64)$ in medical units, $0.31(0.21-0.44)$ in physical medicine and rehabilitation units and $0.03(0.01-$ 0.05) in long-term care facilities (Table 5). Using single linear regression, bad practice for excreta management (score 3) was significantly associated with a high ESBL-PE incidence rate with a coefficient of -0.15 and a $\mathrm{P}$ value of 0.002 (Table 6). Scores related to healthcare units' equipment and HCWs knowledge did not show significant association with ESBL-PE incidence rate. The alcoholic hand rub consumption rate per 1,000 liter was calculated for the different units, with a higher rate for surgical units (Table 5), and showed no significant association with excreta management performance. 


\section{DISCUSSION}

Numerous previous studies identified different risk factors associated with ESBL-PE acquisition in hospital settings [16]. But environmental factors or HCWs practices for excreta management are rarely assessed or neglected for commensal bacteria hosted within the gut microbiota [15]. Although there are many national and international guidelines on the management of healthcare waste for preventing environmental health diseases there are limited global data and information on equipment and excreta management for HCWs. Little data were found from surveys on excreta management in the literature to compare our results.

The major interest of this study was to score the level of equipment in healthcare units, of HCWs knowledge and practices of nurses and assistant-nurses related to excreta management (collection/transport/elimination). Linear regression suggests that bad practice in excreta management could be associated with a high rate of ESBL-PE in healthcare units through environment contamination. This association is debated in the literature, as the link between patient's admission to a room previously occupied by a patient with multidrug-resistant microorganisms seems to be an independent risk factor for acquisition of these bacteria by subsequent room occupants. But this link is unclear for EBLE-PE in comparison with other gramnegative bacteria [17-19]. The compliance of HCWs with standard precautions and the quality of room disinfection including the restroom is probably a key factor for controlling multidrug-resistant microorganisms spread [20,21].

Our results can potentially be explained by the high proportion of bad performance in managing excreta: $29 \%$ of healthcare units were bad-equipped, $30 \%$ of HCWs had low level of knowledge and only $2 \%$ of HCWs had a high level of practices. The two major bad practices were the elimination of 
the excreta and equipment rinsing using a hand shower in the patient's restroom. The first bad practice is due to the lack (or breakdown) of washer disinfectors, or a long distance to the washer disinfector in healthcare units associated with additional bad HCW knowledge. In our study, 57\% of the healthcare units had at least 1 washer disinfector per 21 beds. This rate was slightly lower than that (61\%) observed in a large group of university hospitals in Paris [15]. The second bad practice is due to the old and historic presence of hand showers in French hospitals and their misuse with an unknown high risk of aerosolization by HCWs. This aerosolization of excreta can contaminate the restroom surfaces and HCW hands and gowns. ESBLE-PE can also persist in the environment when HCWs leave patients' rooms and touch doorknobs with gloved hands after excreta collection [22].

The ESBL-PE incidence rates were 0.97 and 0.54 per 1000 patient-days in surgical and medical units, respectively. They were higher than the French national hospital incidence rate $(0.60$ per 1000 patient-days) [7]. In parallel, a higher proportion of HCWs with low level of knowledge and practices (score 3) was also observed in surgical and medical units. The alcohol hand rub consumption rate was low in surgical units in comparison with other units. All those factors may explain the significant association between bad level of HWCs practices and high level of ESBL-PE incidence rate.

There is considerable evidence showing that the environment in health care settings serves as a reservoir for infectious microorganisms. Therefore, strict adherence to basic cleaning and disinfection practices for healthcare settings is essential to prevent cross-transmission of multidrugresistant microorganisms [10]. In recent decades, requirements regarding the disinfection of the environment and medical equipment surfaces have been defined in various European standards and guidelines[23]. Moreover, as most of ESBL-PE positive patients are unknown [16], strict 
compliance with standard precaution is also essential: hand hygiene, personal protective equipment (glove, gown) when necessary and good excreta management.

Our study highlights a need for specific training on this topic for HCWs. Indeed, most of HCWs reported that they had never been trained on excreta management prior to this survey, and $63 \%$ of HCWs requested better training in order to further understand excreta management. These findings may suggest that low level of knowledge could be attributed to poor training of HCWs. In the same way, poor practices may be attributed to the fact that HCWs are unaware of the risk factors for environment contamination during excreta disposal (collection, transport) and the use (disinfection) of equipment for the prevention of environment contamination.

Our study has several limitations. Firstly, we performed a quantitative evaluation and questionnaires were sent to the infection control referent nurses and assistant-nurses in healthcare units. This population can represent a selection bias as it could select participants who had high level of health education. Secondly, interpretation bias can occur with the quality and veracity of the HCWs' answers,, according to their knowledge and practices. Effectively, HCWs may have overestimated their knowledge and practices reading the questions through the study design. Furthermore, participants' responses may have also varied based on their interpretation of a particular statement in the questionnaire: they could not ask the study managers for clarifying the meaning of the questions. Furthermore, assistant-nurses have less initial training in infections and microbiological risks than nurses.

In conclusion, we found that the lack of proper practices on excreta management could be linked to a high ESBL-PE incidence rate in healthcare settings, especially in surgical units. Public health efforts 
to enhance knowledge and practices of HCWs need to be developed and integrated in infection control programs to control the spread of multidrug-resistant microorganisms through the hospital environment. These findings suggest the following recommendations: i) facilities should disseminate policies for appropriate excreta management, ii) strict adherence to these rules is compulsory and must be evaluated, iii) education on excreta management should be provided to nurses and assistant-nurses. Further research is needed to clarify the role of the contaminated hospital environment in the transmission of multidrug-resistant microorganisms from feces. 


\section{ACKNOWLEDGMENT}

We would like to thank all the nurses, assistant-nurses and nurses supervisors for their participation in the study.

\section{CONFLIT OF INTEREST STATEMENT}

None declared 


\section{REFERENCES}

1. Woerther PL, Andremont A, Kantele A. Travel-acquired ESBL-producing Enterobacteriaceae: impact of colonization at individual and community level. J Travel Med. 2017;24(suppl1):S29-S34.

2. Surgers L, Boyd A, Boelle PY, Lalande V, Jolivot PA, Girard PM, Arlet G, Cambier C, Homor A, Decre D, Meynard JL. Clinical and microbiological determinants of severe and fatal outcomes in patients infected with Enterobacteriaceae producing extended-spectrum $\beta$ lactamase. Eur J Clin Microbiol Infect Dis. 2017 ;36:1261-1268.

3. Haverkate M, Derde LP, Brun-Buisson C, Bonten M, Bootsma MC. Duration of colonization with antimicrobial-resistant bacteria after ICU discharge. Intensive Care Med 2014; 40:564571.

4. Birgand G, Armand-Lefevre L, Lolom I, Ruppé E, Andremont A, Lucet JC. Duration of colonization by extended-spectrum b-lactamase-producing Enterobacteriaceae after hospital discharge. Am J Infect Control 2013, 41:443-447.

5. Karanika S, Karantanos T, Arvanitis M, Grigoras C, Mylonakis E. Fecal colonization with extended-spectrum beta-lactamase-producing Enterobacteriaceae and risk Factors among healthy individuals: A systematic review and metaanalysis.. Clin Infect Dis. 2016;63:310-8.

6. Casella T, Nogueira MCL, Saras E, Haenni M, Madec JY. High prevalence of ESBLs in retail chicken meat despite reduced use of antimicrobials in chicken production, France. Int J Food Microbiol. 2017 Sep 18;257:271-275.

7. Arnaud I, Maugat S, Jarlier V, Astagneau P; National Early Warning, Investigation and Surveillance of Healthcare-Associated Infections Network (RAISIN)/multidrug resistance study group. Ongoing increasing temporal and geographical trends of the incidence of 
extended-spectrum beta-lactamase-producing Enterobacteriaceae infections in France, 2009 to 2013. Euro Surveill. 2015;20(36).

8. Magiorakos AP, Burns K, Rodríguez Baño J, Borg M, Daikos G, Dumpis U, Lucet JC, Moro ML, Tacconelli E, Simonsen GS, Szilágyi E, Voss A, Weber JT. Infection prevention and control measures and tools for the prevention of entry of carbapenem-resistant Enterobacteriaceae into healthcare settings: guidance from the European Centre for Disease Prevention and Control. Antimicrob Resist Infect Control. 2017;15;6:113.

9. WHO Guidelines for the prevention and control of carbapenem-resistant Enterobacteriaceae, Acinetobacter baumannii and Pseudomonas aeruginosa in health care facilities, 2017. 74p. ISBN: 978-92-4-155017-8. Available (August 2018) at http://www.who.int/infection-prevention/publications/guidelines-cre/en/

10. Lepelletier D, Berthelot P, Lucet JC, Fournier S, Jarlier V, Grandbastien B; National Working Group. French recommendations for the prevention of 'emerging extensively drug-resistant bacteria' (eXDR) cross-transmission. J Hosp Infect. 2015;90:186-95.

11. Lepelletier D, Andremont A, Grandbastien B; National Working Group. Risk of highly resistant bacteria importation from repatriates and travelers hospitalized in foreign countries: about the French recommendations to limit their spread. J Travel Med. 2011;18:344-51.

12. Ruppé $E$, Andremont $A$. Causes, consequences, and perspectives in the variations of intestinal density of colonization of multidrug-resistant enterobacteria. Front Microbiol. 2013;28;4:129.

13. Guet-Revillet H, Le Monnier A, Breton N, Descamps P, Lecuyer H, Alaabouche I, Bureau C, Nassif X, Zahar JR.Environmental contamination with extended-spectrum $\beta$-lactamases: is 
there any difference between Escherichia coli and Klebsiella spp? Am J Infect Control. 2012;40:845-8.

14. Lerner A, Adler A, Abu-Hanna J, Cohen Percia S, Kazma Matalon M, Carmeli Y. Spread of KPCproducing carbapenem-resistant Enterobacteriaceae: the importance of super-spreaders and rectal KPC concentration. Clin Microbiol Infect. 2015;21:470.e1-7.

15. Lepainteur M, Nérome S, Bendjelloul G, Monteil C, Cottard-Boulle B, Nion-Huang M, Jarlier V, Fournier S; Network of IC Teams of Assistance Publique - Hôpitaux de Paris. Evaluation of excreta management in a large French multi-hospital institution. J Hosp Infect. 2015;91:34650.

16. Jolivet S, Vaillant L, Poncin T, Lolom I, Gaudonnet Y, Rondinaud E, Bendjelloul G, Lomont A, Lucet JC, Armand-Lefèvre L. Prevalence of carriage of extended-spectrum $\beta$-lactamaseproducing enterobacteria and associated factors in a French hospital. Clin Microbiol Infect. 2018 Mar 13. [Epub ahead of print].

17. Nseir S, Blazejewski C, Lubret R, Wallet F, Courcol R, Durocher A. Risk of acquiring multidrugresistant Gram-negative bacilli from prior room occupants in the intensive care unit. Clin Microbiol Infect. 2011;17:1201-8.

18. Ajao AO, Johnson JK, Harris AD, Zhan M, McGregor JC, Thom KA, Furuno JP. Risk of acquiring extended-spectrum $\beta$-lactamase-producing Klebsiella species and Escherichia coli from prior room occupants in the intensive care unit. Infect Control Hosp Epidemiol. 2013;34:453-8.

19. Drees M, Snydman DR, Schmid CH, Barefoot L, Hansjosten K, Vue PM, Cronin M, Nasraway SA, Golan Y. Prior environmental contamination increases the risk of acquisition of vancomycin-resistant enterococci. Clin Infect Dis. 2008;46:678-85. 
20. Carling PC, Von Beheren S, Kim P, Woods C; Healthcare Environmental Hygiene Study Group. Intensive care unit environmental cleaning: an evaluation in sixteen hospitals using a novel assessment tool. J Hosp Infect. 2008;68:39-44.

21. Abreu AC, Tavares RR, Borges A, Mergulhão F, Simões M. Current and emergent strategies for disinfection of hospital environments. J Antimicrob Chemother. 2013 Dec;68(12):271832.

22. Carling PC, Parry MF, Von Beheren SM; Healthcare Environmental Hygiene Study Group. Identifying opportunities to enhance environmental cleaning in 23 acute care hospitals . Infect Control Hosp Epidemiol. 2008;29:1-7.

23. Pitten FA, Werner HP, Kramer A. A standardized test to assess the impact of different organic challenges on the antimicrobial activity of antiseptics. J Hosp Infect 2003;55:108-15. 
Table 1. Evaluation of equipment for excreta management in a large university hospital, France

Items 1 to 13

Healthcare

departments

$N=74(100 \%)$

1. Bedpan washer-disinfector (WD) equipment

$69(93)$

2. Sharing bedpan WD room with other activities and materials

$37(50)$

3. Presence of restrooms in patient room

$58(78)$

4. Presence of hand shower in patient room

5. Sufficient quantity of bedpans

$59(80)$

6. Sufficient quantity of urine bottles

$59(80)$

7. Excreta transport with covered bedpans

$10(13)$

8. Urine transport with covered bottle

$19(25)$

9. Dedicated bedpan for each patient

$38(52)$

10. Dedicated urine bottle for each patient

$38(52)$

11. Presence of alcohol hand rub for hand hygiene in patient's room

$59(80)$

12. Presence of water for hand hygiene in the WD room

$56(76)$

13. Package protective bag for elimination (including gloves and apron)

$56(76)$ 
Table 2. Knowledge evaluation of $688 \mathrm{HCWs}$ related to excreta management in healthcare units

Items 1 to 7

Yes, $\mathbf{n}(\%)$

1. Excreta rinsing in the patient's room is a risk factor for environmental $595(86.4)$ contamination

2. Use of hand shower to clean urine bottle and basins is a major risk factor for $557(80.9)$ environmental contamination

3. Transportation of excreta from patient's room to bedpan washer-disinfector $461(67.0)$ room across public areas needs specific hygiene precautions

4. Use of sealed pockets for urine and fecal collection reduces the risks $390(56.7)$

5. Environmental contamination increases the risk of MDRO outbreak $535(77.8)$

6. Use of a single use materials for excreta collection decreases the risks $458(79.7)$

7. Participation to at least one training related to excreta management $<10$ $83(12.1)$ years

HCWs: Healthcare workers; WD: washer-disinfector; MDRO: multidrug resistant organisms 
Table 3. Practice evaluation of $688 \mathrm{HCWs}$ related to excreta management in healthcare units

$$
\text { Items } 1 \text { to } 15
$$$$
N=688(100 \%)
$$

$$
\text { Yes, } \mathrm{n}(\%)
$$

\section{Always Often Sometimes Never}

\section{In the patient's bathroom}

1. Elimination of urine and feces

2. Use of hand shower to rinse equipment

3. Disinfection of equipment in the restroom

4. Use of cover to transport excreta across HCUs

In the washer-disinfector room

5. Equipment disinfection

6. Daily disinfection

7. Disinfection of materials only at patient's discharge

Use of personal protective equipment for excreta management

8. Gloves

9. Apron

10. Gown

11. Mask

12. No protection

13. Opening the doorknobs with gloved hand

$\begin{array}{llll}158(23) & 199(29) & 186(27) & 145(21) \\ 96(14) & 144(21) & 110(16) & 338(49) \\ 28(4) & 83(12) & 124(18) & 453(66) \\ 83(12) & 138(20) & 206(30) & 261(38)\end{array}$

$158(23) \quad 206(30) \quad 158(23) \quad 166(24)$

$144(21) \quad 213(31) \quad 151(22) \quad 180(26)$

$337(49) \quad 165(24) \quad 76(11) \quad 110(16)$

$616(90) \quad 66(9) \quad 6(1) \quad 0(0)$

$34(5) \quad 48(7) \quad 179(26) \quad 427(62)$

$14(2) \quad 14(2) \quad 220(32) \quad 440(64)$

$28(4) \quad 21(3) \quad 179(26) \quad 460(67)$

$14(2) \quad 21(3) \quad 75(11) \quad 578(84)$

$76(11) \quad 130(19) \quad 241(35) \quad 241(35)$ 
after excreta management

HCUs: Healthcare units

Table 4: Knowledge and practices evaluation of $688 \mathrm{HCWs}$ related to excreta management stratified by type of healthcare units

\begin{tabular}{lcccccc}
\hline Healthcare units (N=74) & \multicolumn{3}{c}{ Knowlegde } & \multicolumn{3}{c}{ Practices } \\
& \multicolumn{3}{c}{ Score* } & & \multicolumn{3}{c}{ Score* } \\
& 1 & 2 & 3 & 1 & 2 & 3 \\
\hline Medical (N=33) (\%) & 27.9 & 44.2 & 27.9 & 3.8 & 75.0 & 21.2 \\
Surgical ( $\mathrm{N}=31$ ) (\%) & 27.3 & 31.4 & 41.3 & 0.0 & 58.2 & 41.8 \\
Rehabilitation (N=5) (\%) & 23.3 & 46.7 & 30.0 & 0.0 & 81.5 & 18.5 \\
Long-term care (N=5) (\%) & 20.0 & 80.0 & 0.0 & 0.0 & 100 & 0.0 \\
\hline
\end{tabular}

*Score 1: high level of performance; score 2: intermediate level; score 3 : bad level. 
Table 5: Incidence rate of ESBL-PE and consumption of alcohol hand rub per 1000 patient-days

\begin{tabular}{lcc}
\hline $\begin{array}{l}\text { Healthcare Units } \\
(\mathrm{N}=74)\end{array}$ & $\begin{array}{c}\text { ESBL-PE Incidence rate / } \\
1000 \text { patient-days }\end{array}$ & $\begin{array}{c}\text { Alcohol hand rub consumption / litre/ } 1000 \\
\text { (Confidence interval) }\end{array}$ \\
\hline Medical $(\mathrm{N}=33)$ & $0.54(0.41-0.64)$ & $41.39(30.05-54.23)$ \\
Surgical $(\mathrm{N}=31)$ & $0.97(0.45-1.12)$ & $25.47(19.23-32.47)$ \\
Rehabilitation $(\mathrm{N}=5)$ & $0.31(0.21-0.44)$ & $20.14(10.20-25.63)$ \\
Long-term care $(\mathrm{N}=5)$ & $0.03(0.01-0.05)$ & $7.37(3.22-7.95)$ \\
\hline
\end{tabular}


Table 6: Simple linear regression model to predict the possible association between performance of equipment, knowledge and practice related to excreta management from 688 healthcare workers and ESBL-PE incidence rate and consumption of alcohol hand rub per 1000 patient-days in 74 healthcare units.

\begin{tabular}{|c|c|c|c|c|c|c|c|c|}
\hline \multirow{3}{*}{$\begin{array}{l}\text { Variable } \\
\text { Equipment }\end{array}$} & \multicolumn{4}{|c|}{ ESBL-PE incidence rate } & \multicolumn{4}{|c|}{ Alcohol hand rub consumption } \\
\hline & \multirow{2}{*}{$\begin{array}{c}\text { Coefficient } \\
0.07\end{array}$} & \multirow{2}{*}{$\begin{array}{c}\text { p-value } \\
0.48\end{array}$} & \multicolumn{2}{|c|}{$95 \% \mathrm{Cl}$} & \multirow{2}{*}{$\begin{array}{c}\text { Coefficient } \\
-4.69\end{array}$} & \multirow{2}{*}{$\begin{array}{c}p \text {-value } \\
0.16\end{array}$} & \multicolumn{2}{|c|}{$95 \% \mathrm{Cl}$} \\
\hline & & & -0.12 & 0.25 & & & -11.3 & 1.99 \\
\hline Knowledge & 0.32 & 0.28 & -0.26 & 0.91 & -1.33 & 0.23 & -3.56 & 0.88 \\
\hline Practices & -0.15 & 0.002 & -0.24 & -0.06 & 2.68 & 0.12 & -0.75 & 6.12 \\
\hline
\end{tabular}

